\title{
A relação dos Engenheiros brasileiros com o Governo Imperial nas obras da CMRSF
}

\author{
Fernanda de Jesus Novais ${ }^{1}$; \\ 1. Bolsista Pevic, Graduando em Engenharia Civil, Universidade Estadual de Feira de Santana, e-mail: \\ nanda_novais15@hotmail.com \\ 2. Ivoneide de França Costa \\ 3. Orientador, Departamento de Letras e Artes, Universidade Estadual de Feira de Santana, e-mail: \\ neidefc@uefs.br
}

PALAVRAS-CHAVE: engenharia, império, engenheiros

\section{INTRODUÇÃO}

No século XIX muitos engenheiros foram contratados para pôr em prática os empreendimentos ligados à modernização de portos, estradas e urbanísticas. Segundo Coelho (1999), a formação dos engenheiros estava voltada para as construções de ferrovias e obras de engenharia civil e arquitetônica, resultantes da demanda dos transportes férreos impulsionados pela cultura cafeeira e do adensamento demográfico nos grandes centros, gerando a necessidade de obras de infra-estrutura. Outro aspecto relevante estava na absorção desses profissionais pela burocracia imperial, sendo esta uma das principais fontes empregadoras da época.

Para atender essa demanda de reformas foram organizadas comissões, uma delas foi a Comissão de Melhoramento do Rio São Francisco (CMRSF). A Comissão de Melhoramento do Rio São Francisco (CMRSF) foi criada em 1883 para executar melhoramentos no rio com objetivo de facilitar a navegação. Os melhoramentos do sistema de navegação fluvial, aliado ao ferroviário e portuário, fariam parte da necessidade do Governo criar vias de locomoção para o transporte de mercadorias e pessoas.

O presente resumo apresenta a relação dos engenheiros brasileiros com o Governo Imperial, no intuito de perceber a função dos engenheiros nas obras da CMRSF e como os trabalhos dos engenheiros eram reconhecidos.

\section{MATERIAL E MÉTODOS OU METODOLOGIA (ou equivalente)}

Pesquisa bibliográfica para identificação dos engenheiros. Tal pesquisa foi realizada na documentação pertencente ao projeto de pesquisa ao qual o plano se vincula. Para complementar a pesquisa foi feito estudos em outras fontes bibliográficas sobre o tema.

\section{RESULTADOS E/OU DISCUSSÃO (ou Análise e discussão dos resultados)}

Comissão de Melhoramento do Rio São Francisco (CMRSF) foi criada em 1883 para por em prática os melhoramentos do rio a partir dos estudos feitos pela CHI. A comissão foi composta por engenheiros brasileiros aproveitando, inclusive, alguns que trabalharam na CHI. A primeira equipe foi chefiada pelo Antonio Plácido Peixoto do Amarante com a participação dos engenheiros Theodoro Fernandes Sampaio, João Emiliano Amarante, Evaristo Galvão Filho, João Felix Peixoto de Azevedo Sobrinho, Themístocles Pompeu de Albuquerque Figueiredo, Brotero Frederico de Macedo Costa, Antônio Julio de Gouvêa, além do médico Guilherme Lassance Marback. O objetivo era de realizar obras de desobstrução no trecho compreendido especificamente entre o Porto de Jatobá (atual Petrolândia), Pernambuco e a cachoeira do Sobradinho, na Bahia, cuja extensão era de $428 \mathrm{Km}$, onde seriam construídos canais para permitir a navegação 
devapores com até 40 metros de comprimento. As atividades da CMRSF se estenderam atéo ano de 1896, quando foi dissolvida.

Os trabalhos da Comissão de Melhoramento do Rio São Francisco foram iniciados em 1883 com sondagens, levantamento de plantas, nivelamento e determinação da velocidade das correntes marítimas no rio, seguido com o serviço de desobstrução e da construção dos diques.

A CMRSF foi composta por engenheiros brasileiros, identificou-se os primeiros engenheiros e suas formações; algumas atividades desenvolvidas, a saber:

- Antonio Plácido Peixoto do Amarante - nasceu no Distrito de Santo Antonio do Rio Abaixo, atual cidade de Santo Antônio para Leverger, em MT. Filho de Tenente Antonio José Zeferino Amarante e D. Ana Baubina de Amarante, formou-se Bacharel em Ciências Matemáticas e Físicas. Amarante fez parte da Comissão Hidráulica do Império, ocupando o cargo de primeiro engenheiro. Trabalhando posteriormente na Estrada de Ferro da Bahia. Em 1883, foi engenheiro chefe da Comissão de Melhoramentos do Rio São Francisco.

- Theodoro Fernandes Sampaio, $1^{\circ}$. engenheiro (transferido de ajudante de $1^{\mathrm{a}}$. classe no prolongamento Estrada de Ferro da Bahia), Após ter concluído os estudos preparatórios, ingressou na Escola Central, em 1872. Cursou as disciplinas da área de Ciências Físicas e Matemáticas, tornando-se depois habilitado a cursar Engenharia Civil. Em 1874, com a separação da Escola Central, bacharelou-se em Engenharia Civil.

- Augusto Ferreira Ramos, condutor (transferidor de condutor no prolongamento da Estrada de Ferro da Bahia); Engenheiro civil, sanitarista e economista brasileiro nascido no Estado do Rio de Janeiro, que projetou (1908) o ousado caminho aéreo para o Pão de Açúcar, através de teleféricos, ligando os morros da Babilônia, Urca e Pão de Açúcar. Formado em Engenharia Civil pela Escola Politécnica do Rio de Janeiro (1882),

- João Emiliano Amarante, engenheiro (transferido de condutor de $2^{\circ}$. condutor no Prolongamento da Estrada de Ferro da Bahia); Engenheiro, filho de Antonio Plácido Peixoto do Amarante

- Evaristo Galvão Filho, engenheiro auxiliar, promovido em 1884 a condutor (primeira nomeação);

- Reginaldo Candido da Silva, engenheiro auxiliar (transferido de outra obra).

O Governo que absorvia a maior parte dos formados em engenharia. Os engenheiros eram parte de um projeto de unia o pensamento do Governo Imperial na formação de uma nova ordem centrada nos valores de progresso e civilização cuja concepção era a promoção do domínio da natureza, demarcações de fronteiras, construção de meio de comunicação e urbanização. Diante dessa perspectiva organizacional, na qual os engenheiros assumiam o papel de executores dos projetos do Governo Imperial na implementação do progresso material, preconizava-se o reconhecimento $\mathrm{e}$ aproveitamento dos recursos naturais e a organização dos meios urbanos. Ao mesmo tempo, a situação contribuía para a consolidação da profissão do engenheiro (COSTA, 2014).

\section{CONSIDERAÇÕES FINAIS (ou Conclusão)}

No século XIX, uma das principais fontes empregadoras dos engenheiros era burocracia imperial nas obras de melhoramentos, o que veio a conferir ao profissional legitimar seus conhecimentos e ascensão intelectual. A criação de Comissões para realizar os melhoramentos sempre foi uma prática comum nos períodos colonial e 
imperial. A palavra melhoramento era utilizada inclusive para compor nomes das próprias comissões (COSTA, 2014). Com isso, o Governo Imperial mantinha relações estreitas com a engenharia da época.

\section{REFERÊNCIAS}

ANRJ. 5F 564, maço 147, documento $n^{\circ}$. 1. ANRJ. 5F 564, maço 146. Relação dos materiais da extinta Comissão de Melhoramento do Rio São Francisco entre a Diretoria da Estrada de Ferro de São Francisco.

ANRJ. CMRSF 5F 564, maço 145, documento no .5

COSTA, Ivoneide de França. Profissionalização dos engenheiros no século XIX: atividades e regulamentação. In: Eletrônicos do $14^{\circ}$ Seminário Nacional de História da Ciência e da Tecnologia - $14^{\circ}$ SNHCT. Belo Horizonte, Campus Pampulha da Universidade Federal de Minas Gerais - UFMG 08 a 11 de outubro de 2014 I ISBN: 978-85-62707-62-9

MOTTA, Jehovah. Formação do Oficial do Exércíto (Currículos e regimes na Academia Militar). Rio de Janeiro: Companhia Brasileira de Artes Gráficas, 1976, 368 p.

SAMPAIO, Theodoro Fernandes. Diário 1878-1879. Arquivo Theodoro Sampaio. IGHB. Sem paginação. Diário a Comissão Hidráulica: Rio São Francisco: de 20 março a 31 de agosto 1879. Instituto Geográfico de Histórico da Bahia. 1879

TELLES, Pedro Carlos da Silva. História da engenharia no Brasil. Rio de Janeiro: Livros Técnicos e Científicos, 1984. 